\title{
THE REACTION OF HUMAN DUODENAL CONTENTS TO ACID AND ALKALINE MEAT MIXTURES
}

\author{
By STACY R. METTIER
}

(From the Thorndike Memorial Laboratory, Boston City Hospital, and the Department of Medicine, Haroard Medical School, Boston)

(Received for publication January 13, 1930)

The hydrogen ion concentration of the intestinal contents has received considerable attention during the past few years in regard to abnormalities of inorganic metabolism. It has been shown that the $\mathrm{pH}$ of the medium probably has an important influence on the absorption of calcium, phosphorus, and possibly iron and magnesium $(1,2,3)$. The studies reported in this paper were undertaken to determine whether a predigested beefsteak meal had sufficient buffer quality, when fed at widely divergent hydrogen ion concentrations, to serve satisfactorily as a means of altering experimentally the $\mathrm{pH}$ of the upper intestinal tract of man. A preliminary report has been published (4) on the effect of ingested iron on blood formation as influenced by feeding simultaneously predigested beefsteak at one or another $\mathrm{pH}$. In order to determine how far the method was capable of altering the reaction of the upper gastro-intestinal tract, fractional duodenal and gastric analyses were made on five patients after they were fed by stomach tube a predigested beefsteak meal as an acid mixture and after they were given on a subsequent day this food as an alkaline mixture. In three of the patients before the beefsteak was fed, achylia gastrica was demonstrated after the use of histamine, whereas the other two patients showed a normal amount of free and combined hydrochloric acid in a fractional gastric analysis following the administration of an alcohol test meal.

\section{METHOD}

Beefsteak, from which had been removed as much fat as possible, was put through a special grinder that removed the muscle from the connective tissue. To 200 grams of the separated meat was added $200 \mathrm{cc}$. 
of tepid water, 4 grams of pepsin and sufficient hydrochloric acid to adjust the mixture to $\mathrm{pH} 3$. This mixture was incubated at $37^{\circ} \mathrm{C}$. for 2 hours and at the end of this time poured through a sieve containing 12 square holes to the inch. The mixture was then kept at $\mathrm{pH} 3$ or 3.2 , when fed as an acid meal or brought to $\mathrm{pH} 8$ with concentrated sodium hydroxide for use as an alkaline meal. Vomiting was induced when a meal was fed that was more acid or more alkaline than mentioned above.

During the period of incubation of the beefsteak mixture the patient was prepared for study. A small caliber tube was passed slowly into the duodenum according to the procedure described by Rehfuss (5). The position of the tip of the tube was checked by means of the fluoroscope and in all instances was found in the descending portion of the duodenum.

A tube was then passed through the nose into the stomach and by this means the meat mixture was administered and samples of the gastric secretion obtained. In order to minimize gastric stasis the patient was placed on his right side.

The duodenal contents were withdrawn prior to feeding in all but one instance, and then none could be obtained after repeated trial. The time interval between the feeding and the appearance of the mixture in the duodenum was noted and from then on samples of duodenal and stomach contents were removed every 15 or 20 minutes.

The hydrogen ion concentration expressed in $\mathrm{pH}$ was determined on all of the specimens by the colorimetric method (6). This technic has been shown by Grayzel and Miller (7) to be sufficiently accurate for the purpose of these studies.

\section{RESULTS}

The results in the 3 patients with achylia gastrica were entirely similar but differed from those in the 2 patients with a normal gastric secretion. However, the results in the latter 2 patients were identical. Sample results of the duodenal analyses are recorded in the figures to show the variation of the hydrogen ion concentration in the duodenum following the administration of an acid and an alkaline predigested muscle meat meal to patients with and without free hydrochloric acid in their gastric secretions. The reaction of each type in patients with 


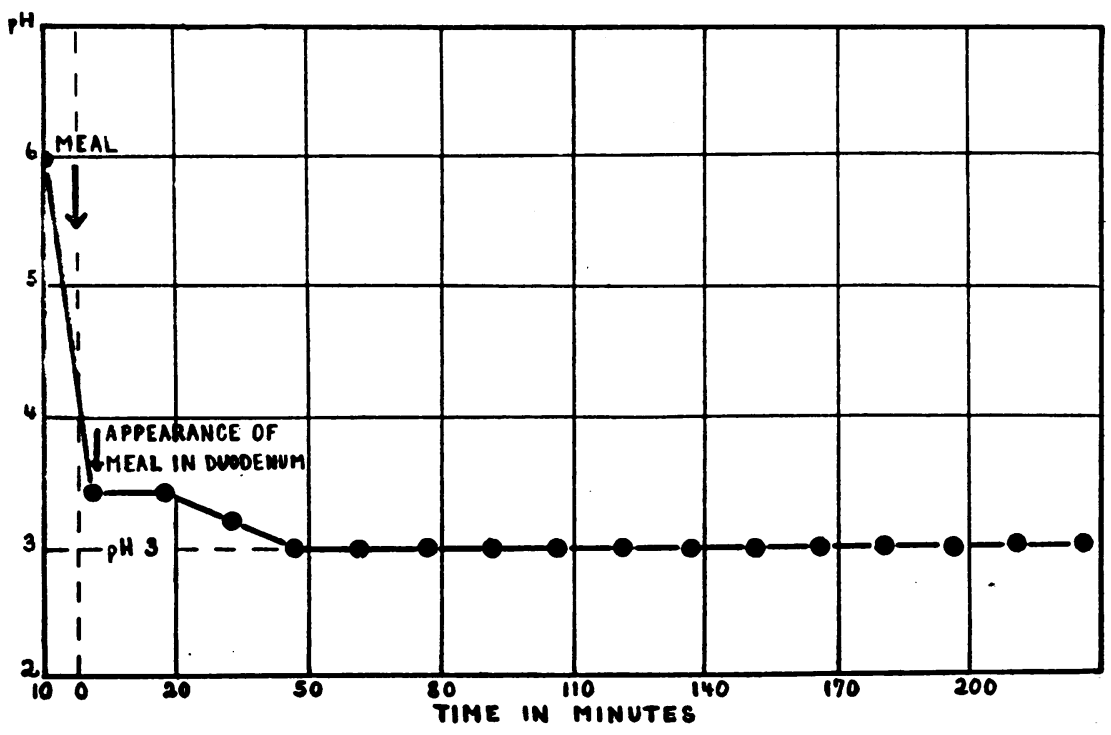

Fig. 1. Fractional Duodenal Analysis Following the Feeding of 200 Grams of Predigested Beefsteak Fed at pH 3.0 to a Patient with Achylia Gastrica

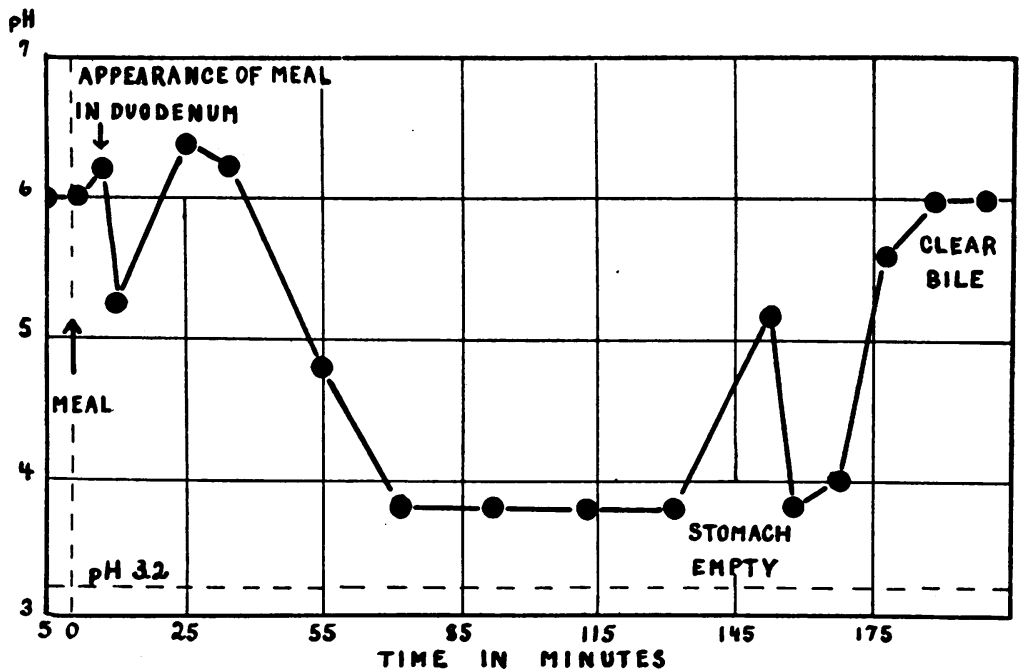

Fig. 2. Fractional Duodenal Analysis Following the Feeding of 200 Grams of Predigested Beefsteak Fed at pH 3.2 to a Patient with Normal Gastric Secretion 
similar gastric analyses were of the same character, and examples are shown in figures 1 and 3 for patients with achylia gastrica and in figures 2 and 4 for patients with a normal gastric secretion.

The time interval between the feeding of either an acid or alkaline meal and its appearance in the duodenum was rather constant. This interval was between 3 and 5 minutes except once when after the feeding of an acid meal to a patient with achylia gastrica it was 9 minutes. There was thus no significant difference in the time it took the meal to reach the duodenum in patients with a normal gastric secretion, and in those with achylia gastrica.

Following the administration of the acid beefsteak meal there was a slow drop in the $\mathrm{pH}$ of the duodenal contents from about $\mathrm{pH} 6$ to $\mathrm{pH}$ 4 , or under and following the alkaline meal a slow rise from about $\mathrm{pH} 6$ to $\mathrm{pH} 7.6$, or 8 . The change in the hydrogen ion concentration was not sudden, but a slow process, that took from 10 to about 30 minutes before a maximum or minimum $\mathrm{pH}$ was reached, which showed slight individual variation. Sometimes the duodenal contents reached a $\mathrm{pH}$ value equivalent to that of the administered meal. In other instances the contents failed to become as acid or alkaline as the meal itself, although always the $\mathrm{pH}$ was altered distinctly towards that of the preparation fed. Thus the duodenal contents were rendered either definitely acid, $\mathrm{pH} 4$ or under, or alkaline, $\mathrm{pH} 7.6$ to $\mathrm{pH} 8$.

After the duodenal contents had become acid or alkaline the meat mixture was capable of maintaining an almost constant $\mathrm{pH}$ for a period of $1 \frac{1}{2}$ to about 4 hours. The longer periods of this more or less constant reaction occurred in patients with achylia gastrica. This suggests that the duration of the process may be dependent upon the gastric acidity. After the stomach had become empty, clear bilestained fluid was obtained from the duodenum. The $\mathrm{pH}$ determinations on specimens obviously containing bile showed a return in hydrogen ion concentration to essentially that at the commencement of the experiment.

Samples of gastric contents taken immediately after the administration of an acid or alkaline meat meal to patients with and without free hydrochloric acid in their stomachs showed a $\mathrm{pH}$ equivalent to that of the meal. A meal fed at $\mathrm{pH} 8$ to patients with a normal gastric secretion remained at that $\mathrm{pH}$ for about 2 hours before the stomach 
hydrochloric acid rendered it acid. This type of meal fed to patients with achylia gastrica caused no change in the $\mathrm{pH}$ of the gastric con-

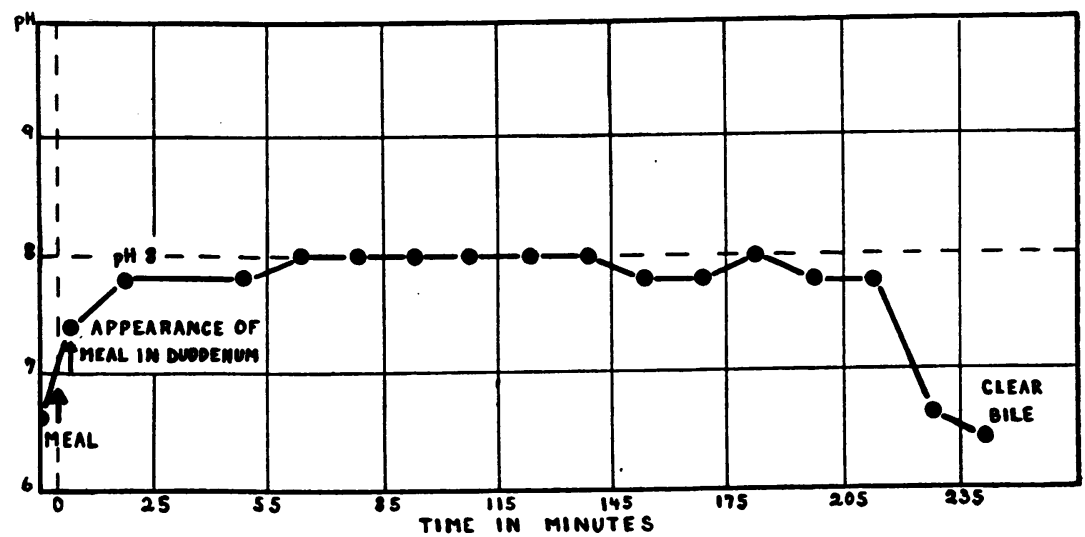

Fig. 3. Fractional Duodenal Analysis Following the Feeding of 200 Grams of Predigested BeEfsteak Fed at PH 8 to a Patient with Achylia Gastrica

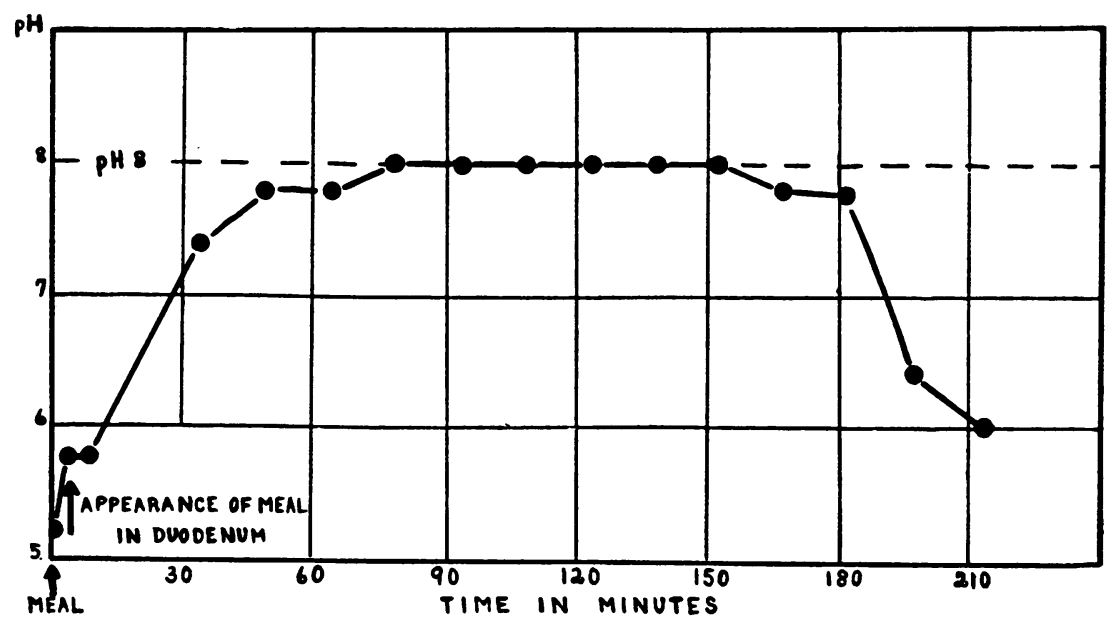

Fig. 4. Fractional Duodenal Analysis Following the Feeding of 200 Grams of Predigested BeEfsteak Fed at pH 8 to a Patient with Normai Gastric Secretion

tents from the time it reached the stomach to when no more meat could be withdrawn or for a period of from 2 to 3 hours. The acid 
meal fed to patients with achylia gastrica remained in the stomach at a constant $\mathrm{pH}$ for a period of 3 to $3 \frac{1}{2}$ hours or until the stomach was empty, whereas in patients with free hydrochloric acid in their gastric secretions the stomach became empty between $1 \frac{1}{2}$ to 2 hours after the beefsteak was fed. The predigested beefsteak meal, therefore, when fed at $\mathrm{pH} 8$ was capable of rendering the gastric contents alkaline for a period of 2 to 3 hours and when fed at $\mathrm{pH} 3$ or 3.2 remained acid for $1 \frac{1}{2}$ to $3 \frac{1}{2}$ hours or until the stomach became empty.

\section{DISCUSSION}

A considerable amount of work has been done on the hydrogen ion concentration of the duodenal contents of dogs and apparently the normal range in $\mathrm{pH}$ is from 6.2 to 6.5 (3). The results of such analyses in man have been in variance. Graham and Emery (8) in a review of the literature note that some investigators have obtained a figure for the normal duodenal $\mathrm{pH}$ of 4.56 , whereas others have recorded the reaction to be slightly alkaline, but no mention is made as to whether achylia gastrica was present or not in the patients. The evidence is that the reaction of the duodenum tends normally to be acid. Comparatively little is known of the physiological factors that may alter the hydrogen ion concentration of the duodenal contents. Pawlow (9) has stated that the alkalinity of pancreatic juice varies considerably, apparently according to differences in the character of food ingested. The various observations suggest that there may occur considerable individual variation in the duodenal reaction and one may speculate that such changes may lead to abnormalities of inorganic metabolism because of the probable importance of an optimal $\mathrm{pH}$ in the gastro-intestinal tract for the absorption of chemical elements. Individuals lacking a normal gastric secretion of hydrochloric acid may thus deprive all or some part of the intestine of a sufficient degree of acidity over a proper amount of time to insure suitable solubility and absorption of inorganic and other substances.

\section{SUMMARY}

Two hundred grams of predigested beefsteak adjusted to $\mathrm{pH} 3$ or 3.2 were fed to 3 patients with achylia gastrica and to 2 patients with a normal gastric secretion. On a subsequent day a similar amount of beefsteak was adjusted to $\mathrm{pH} 8$ and fed to the same individuals. 
Simultaneous fractional duodenal and gastric analyses showed that the acid meal was an effective means of rendering the gastro-duodenal contents acid, over a range of $\mathrm{pH} 4$ or under and the alkaline meal rendered the contents alkaline, $\mathrm{pH} 7.8$ to 8 . The alkaline $\mathrm{pH}$ was maintained almost constant for a period of 2 hours in the stomach and duodenum of patients with free hydrochloric acid in their gastric secretion and from 2 to 3 hours in patients with achylia gastrica. The acid $\mathrm{pH}$ was maintained almost constant for a period of from $1 \frac{1}{2}$ to 2 hours in patients with a normal gastric secretion, and from 3 to 4 hours in patients with achylia gastrica.

The predigested beefsteak meal may be used experimentally in the study of the relation of hydrogenion concentration of the upper intestinal tract to inorganic metabolism.

\section{BIBLIOGRAPHY}

1. Bergeim, O., J. Biol. Chem., 1926, lxx, 35, 51. Intestinal Chemistry. VII. The Absorption of Calcium and Phosphorus in the Small and Large Intestines.

2. Irving, L., J. Biol. Chem., 1926, lxviii, 513. The Relation of Solubility to the Absorption of Calcium Salts from the Intestine.

3. Grayzel, D. M., and Miller, E. G., Jr., J. Biol. Chem., 1928, lxxvi, 423. The $\mathrm{pH}$ of the Contents of the Gastro-Intestinal Tract in Dogs, in Relation to Diet and Rickets.

4. Mettier, S. R., and Minot, G. R., Proc. Am. Soc. Clin. Invest., J. Clin. Invest., 1929, vii, 510. The Effect of Iron on Blood Formation as Influenced by Changing the Acidity of the Gastric Contents in Certain Cases of Anemia.

5. Rehfuss, M. E., Diagnosis and Treatment of Diseases of the Stomach. W. B. Saunders and Co., Philadelphia, 1927.

6. Clark, W. M., The Determination of Hydrogen Ions. Williams and Wilkins Co., Baltimore. Second Edition, 1923.

7. Grayzel, D. M., and Miller, E. G. Jr., Proc. Soc. Exper. Biol. and Med., 1927, xxiv, 668. $\mathrm{pH}$ Concentration of Intestinal Contents of Dog, with Special Reference to Inorganic Metabolism.

8. Graham, W. R., and Emery, E. S., Jr., J. Lab. and Clin. Med., 1928, xiii, 1097. The Reaction of the Intestinal Contents of Dogs Fed on Different Diets.

9. Pawlow, I. P., The Work of the Digestive Glands. Translation by Thompson, W. H., Charles Griffin and Co., London, 1902. 